\title{
A Study of Nail Contents Design based on the Women's Psychology and Emotion
}

\author{
Hee Jung Seo ${ }^{1}$, Joon Seub Cha ${ }^{2}$ and Sung Kwan Kang ${ }^{3}$ \\ ${ }^{1}$ Dept .of Interdisciplinary Program of Perfume and Cosmetics Chonnam National \\ University Gwangju, Korea \\ ${ }^{2}$ Dept. of Internet Contents, Honam University, Gwangju, Korea \\ ${ }^{3}$ Intersave. co., Ltd, Gwangju, Korea \\ genjo16@hanmail.net,jscha7@hotmail.com, silicon1@hanmait.net
}

\begin{abstract}
Women usually put much effort to present themselves better with the help of cosmetics or clothes. Today, the interaction between color and psychology is being utilized in treatment of stress and depression.

This study aims to design a mobile app that can provide the most suited nail design for women's condition based on the relationat gralysis of psychology and color choice.

A designed app offers recommendations in comprehensive consideration of factors such as weather, season, women's psychology and preference toward color and texture and is customizable according to the matching analysis between expert's recommendation and customer's choice.
\end{abstract}

Keywords: Nail, App, Emotion, Psychology

\section{Introduction}

21 century's information seciety, the age of emotion and image, has brought the attention to colors. Singles and workng moms are growing in numbers in our society, many of whom choose to have jobs for timancial freedom or self-fulfillment, and are very much interested in increasing their personal value.

Many factors contribute to form a person's impression and image but the primary one would be appearance. Women usually put much effort to present themselves better with the help of cosmetics or clothes [1].

Preference of color can be affected by ethnicity, region, season, environment, experience, psychology, gender, age, and customs, which in color psychology is interpreted as that color has a meaning and reflects mind. This interaction between color and psychology is being utilized in treatment of stress and depression.

In this regard, this research aims to identify women's nail color preference according to their psychology, eventually contributing to customer satisfaction and marketing. Also, women's psychology behind color and texture preference was analyzed. The Nail App was designed to recommend nail design suitable for specific users based on the matching analysis between recommendations and their choice. 


\section{Women's Psychology and Emotion}

\subsection{Women's stress}

Stress is a physiological reaction that occurs when a unbalance between imposed demands and ability to fulfill the requirements was perceived.

Stress is complexly related to psychological and emotional process. External demands become the source of stress and, the biological response to this stress is known to have significant effect our mental health during the complex process of recognition and emotion [2].

Women's stress is mostly covered in terms of daily environment and Korean women's main issues involve spouse, family, interpersonal relationship, finance, housework health etc.

\subsection{Women's depression}

Women's depression is not only related with social roles and interpersonal adaptation but also with socio-economic factors such as marital status edycational background and stress, social support [3].

As to women's depression, there is a negative relation between age and mental health, that is, older women are more likely to suffer from depression. In addition, married, middle aged women are more inclined to experience higher stress leveland depression than single man and woman or married man [4]. Also, women's recognition and social support regarding their environmental surroundings such as life experience-andiving conditions are known to have a considerable effect on depression [5]

These studies showed that women sdepression is difference by factors like age, education, job and financial status. In general, if the Ceducation level and economic level is high, depression is lowered.

\subsection{Women's self-esteem}

Self-esteem plays a vital role in psychological territory, working as a buffer to stress. People with lower self-esteem tend to experience anxiety, depression, physical symptoms more [6]. People with high self-esteem and low self-esteem both respond positively toward positively stressful situations. People with low self-esteem respond negatively to negative situation. On the other hand, people with high self-esteem are less affected by negative stress by rejecting or controlling the negatively stressful situation.[7].

Thus, self-esteem controls the levels of stress or depression and people with low selfesteem suffers more severe depression from negative experiences than people with high selfesteem do.

\subsection{Color and season[8]}

Spring can be represented by colors of yellow and pink which can be seen from young leaves and flower blossoms. In spring, vivid colors can be chosen with yellow as the basic color that can be matched with yellowish green for green type, vermilion for red type, and coral for pink type. Spring colors are mostly primary colors with high brightness and chroma that give shiny, gorgeous, lively, and energetic feels.

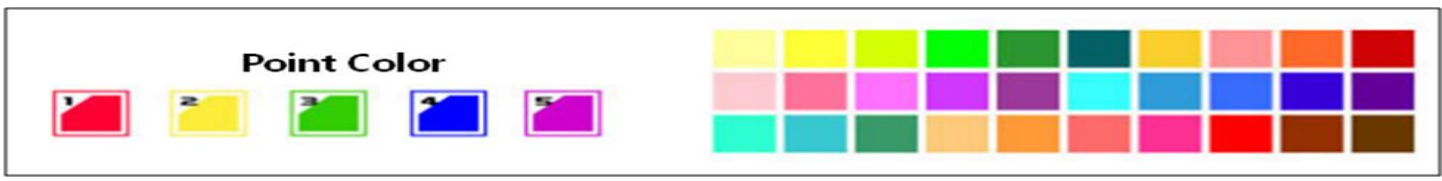

Figure 1. Spring Color 
Summer can be represented by colors of white and blue that can be seen from sea, mountain ridge, and morning glory. In summer, white can be chosen as the basic color that matches well with the soft pastel tone or intermediate tone of dark blue, purple, pink. Summer colors may slightly lack vividness but they still are bright.

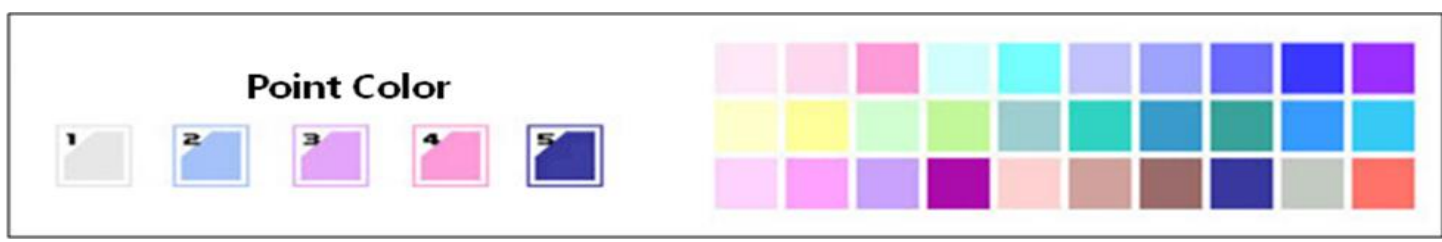

Figure 2. Summer Color

Autumn can be represented by the color of gold that can be seeprom Cosmos and ripe fruits. In autumn, gold can be chosen as the basic color that matches well with gradation colors of green, gold, and red. Autumn colors are low $\mathrm{m}$ brightness and chroma that give feels of deepness, fullness, and transparency.



Figure 3. Autumn Color

Winter can be represented by the colors of blue and black that can be seen from fallen leaves and northerly wind. In winter, black matches well with gorgeous and strong colors such as red, blue, green, and purple that are bright and lively. Winter colors are mainly dark, vivid and high in chroma and brightness. Also, they show strong contrast of bright and cark, which gives clear overall images and gorgeous images with clear and cold primary colors.

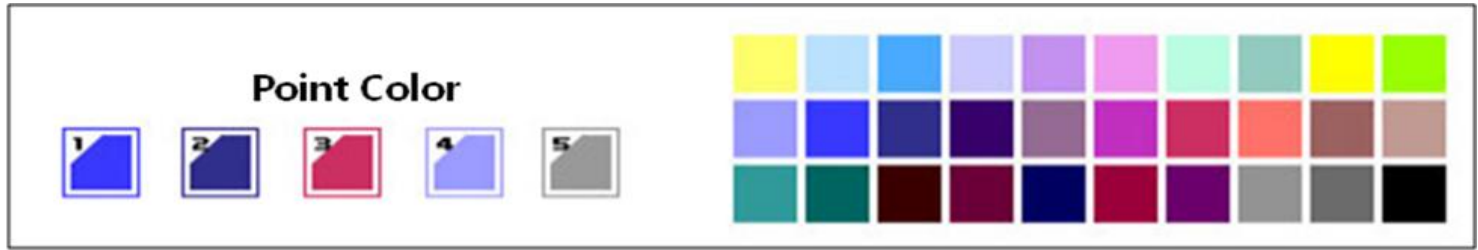

Figure 4. Winter Color

\section{Nail app design}

\subsection{Existing Nail app}

OPI App and glory App have various colors and textures, provide virtual experience function for users to try on the apps, and let the users to upload them. 


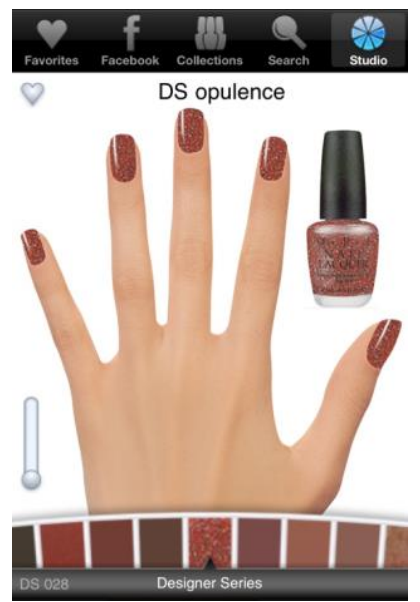

(a) OPI App

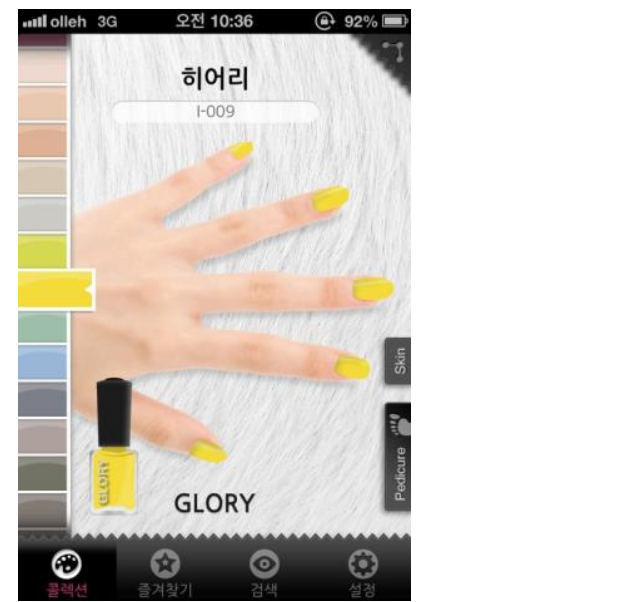

(b) Glory App

Figure 5. Nail App List I

The SaraNail app offers pictures of nail antists' works and video clips showing their process, lets user to register and post their gwn nail art pietares on gallery, and share with others through Facebook or Twitter. Also, it provides news on event or seminar of related shopping malls or academies and information on recommended local nail shops.

The Nail Book app offers similar, functions and has users participation features like rankings of popular nail arts by users rating.

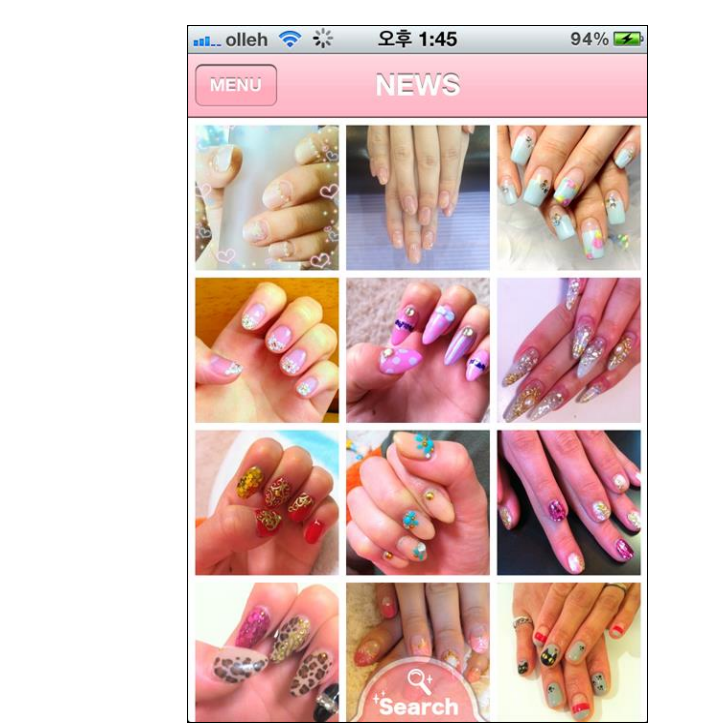

(a) Nail Book



(b) SaraNail App

Figure 6. Nail App List II

\subsection{Nail app design}

In this research, a nail application was designed based on the following survey results which built upon previous research [9] on women's preference of nail colors and psychology. The goal was to even have a function of identifying users' psychology as opposed to existing applications which simply offer functions of making or showing nail works 
Table 1. Nail Color and Women's Psychology

\begin{tabular}{|c|c|}
\hline Item & Research Result \\
\hline Criteria of Purchasing Nail Colors & $\begin{array}{l}\text { Group with average confidence in appearance focused } \\
\text { more on colors }\end{array}$ \\
\hline Factors Affecting Purchasing Needs & $\begin{array}{l}\text { Group with high interest in appearance and nail colors } \\
\text { showed higher purchasing needs }\end{array}$ \\
\hline Factors Affecting Color Choice & $\begin{array}{l}\text { Group with high confidence in appearance preferred colors } \\
\text { in vogue/ Group with hangnail chose according to how they } \\
\text { feel at the moment }\end{array}$ \\
\hline $\begin{array}{l}\text { Factors Affecting Change of Color } \\
\text { Choice }\end{array}$ & $\begin{array}{l}\text { Group with high interest in appearance and colors changed } \\
\text { more in their color choices }\end{array}$ \\
\hline Tendency to Purchase Colors & $\begin{array}{l}\text { Group of } 30 \text { s and } 40 \text { s showed tendency to purchase similar } \\
\text { colors }\end{array}$ \\
\hline $\begin{array}{l}\text { Match of Color Preference and Nail } \\
\text { Color }\end{array}$ & $\begin{array}{l}\text { Pink was preferred as an ordinary colo and red or blue } \\
\text { were avoided for lacking the sense of laste. no personality }\end{array}$ \\
\hline $\begin{array}{c}\text { Relatedness of Purchase Criteria and } \\
\text { Mental State }\end{array}$ & $\begin{array}{l}\text { Group depressed with health problems focused on popular } \\
\text { colors and brands/ Group with low self-esteem focused on } \\
\text { colors/ Group patientily responding to stress focused on } \\
\text { function or quality }\end{array}$ \\
\hline $\begin{array}{l}\text { Purchasing Power According to } \\
\text { Mental State }\end{array}$ & $\begin{array}{l}\text { Group depressed with low selifesteem and health problems } \\
\text { have low pyrchasing power/ Positive and negative self- } \\
\text { image both showed high purchasing power }\end{array}$ \\
\hline
\end{tabular}

The application designed in this resêrch provides analysis of users' mental state based on their choice of color, shape, and texture; then puts current weather, time, and season into consideration with the result of this analysis; and finally offers recommendation of nail color. Figure 3 demonstrates the Nail App's screen. The app consists of following activities: Select function for virtually appleing the color and texture choice on fingernails, Color function for color choice, Texture function for texture choice, Edit function for personal nail design, List function for viewing previously created nail designs, and Mental function for viewing the matching results and analysis.

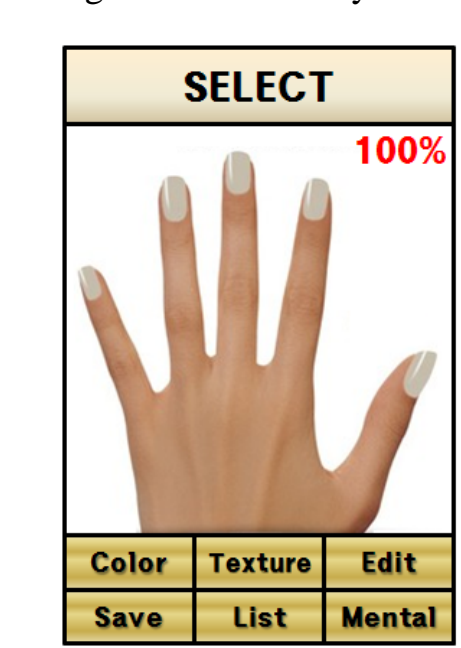

(a) Select activity



(b) Color activity

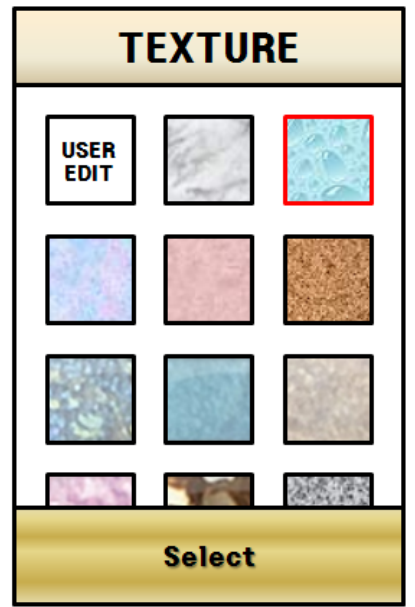

(c) Texture activity 


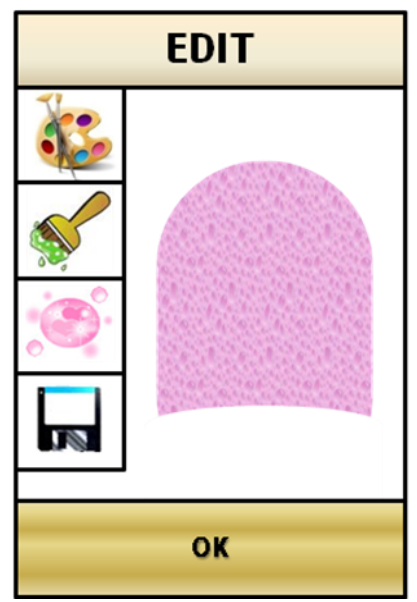

(d) Edit activity

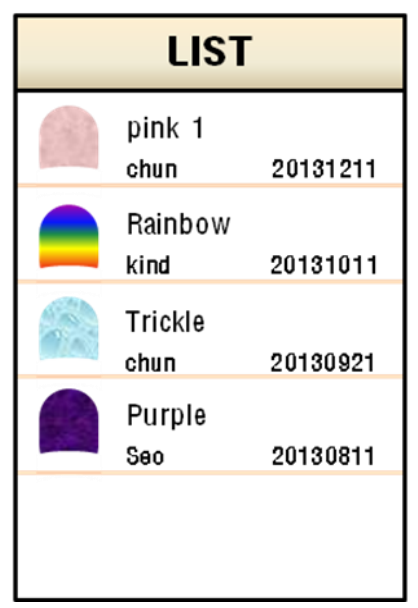

(e) List activity

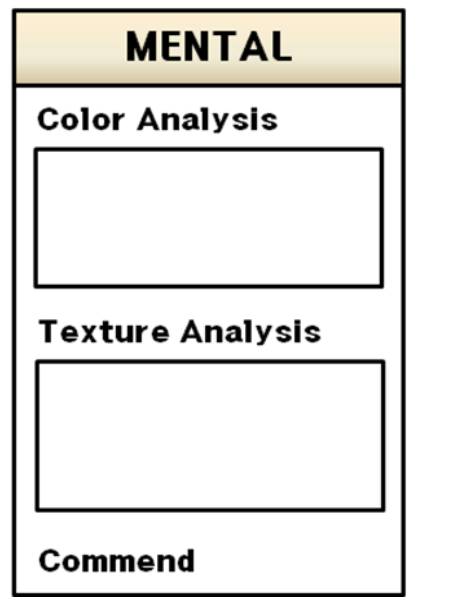

(f) Mental activity

Figure 7. The designed activity

Figure 8 shows the algorithm that calculates the matching rate between user's nail design and the Nail App's recommendation on the screen. The designed Nail App searches for related information (weather, humidity, season, temperature, etc.) through network, then turn it into XML data, and bring them into the app. The XML data transmitted into the app is analyzed; and suitable color and design for qaifare extracted, from which a list of recommended design is created.

When a user set own design, then the Nailapp calculates and shows the matching rate between the user's design and the app's recommended design. This can apply on a recommended design by others and onesell.

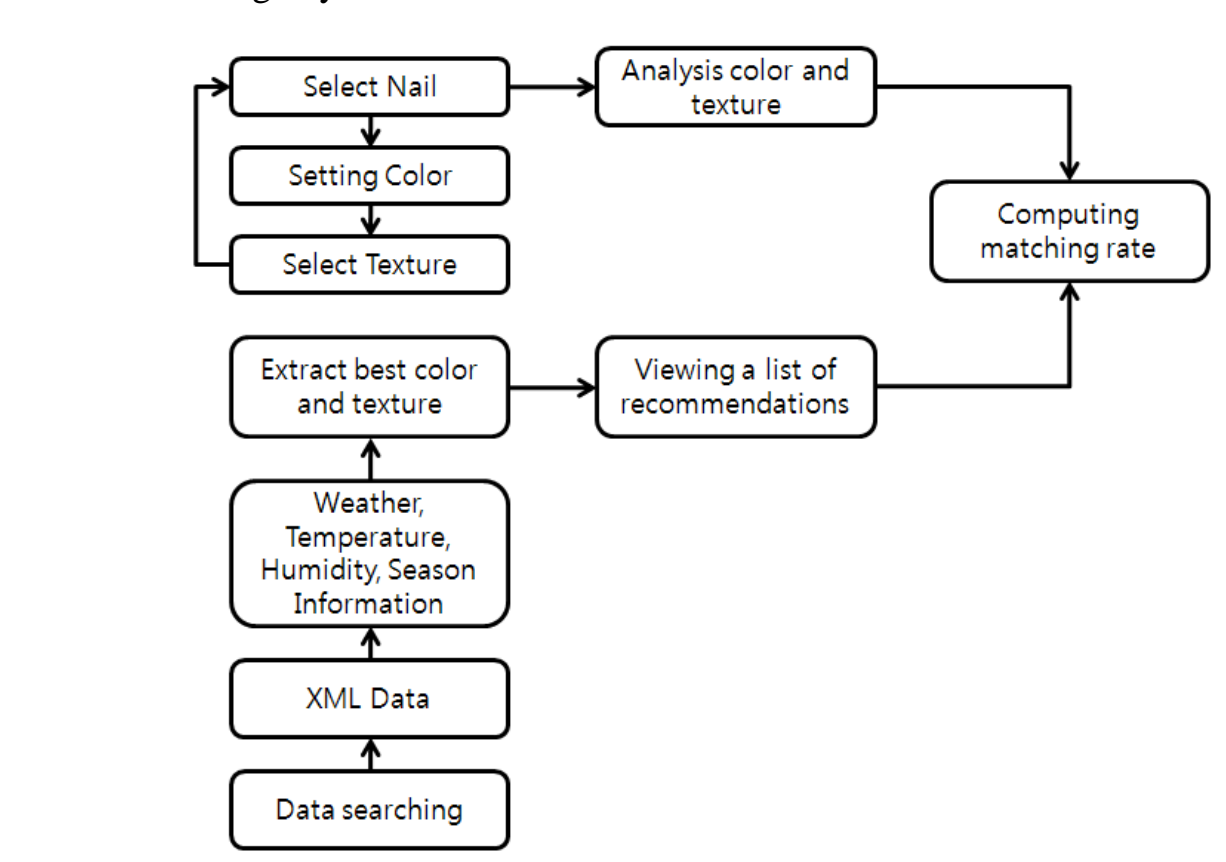

Figure 8. Computing algorithm for the matching rate 
In Figure 8, the user's design is virtually applied on fingernails and the matching rate between the user's design and the app's recommended design. The user can check out the related information on the color and texture of the design by tapping the Mental menu.

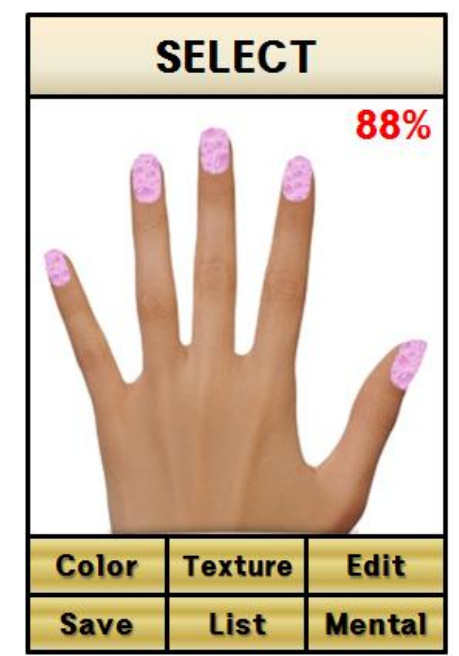

(a) Result activity

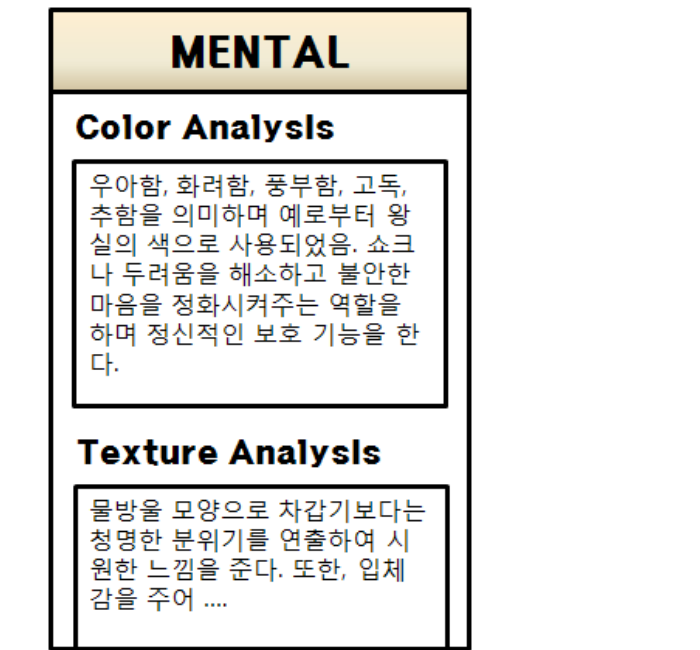

(b) Analysis data

\section{Conclusion}

\section{Figure9. Final result}

This research was designed to identify women's preference for nail colors in relation to their mental state, eventually contributing to customer satisfaction and marketing. Also, a mobile application called the Nail ApR was designed. The app provides the analysis of women's mental state based on their color and texture preference, offers recommendations in comprehensive consideration of Tactors such as weather and season, and gives matching analysis between user's choice and the app's recommendation.

The result of this research could provide essential data to identify the correlation between women's psychology and nail color preference, which can be utilized for 1:1 customer response in nail salon, marketing tool, color study, product development.

In later research a comprehensive nail app based on the integration of existing study and new algorithm that can take photos of user's hand with smart phone, analyze them, and determine the most suitable nail design will be developed.

\section{References}

[1] S. G. Shin and S. M. Whang, "The Application of Sensibility and Psychological Test Techniques for the Study of Preference Behavior of Color Cosmetic Product", Journal of Korea Society of Color Studies, vol. 11, no. 1, (1998).

[2] T. Cassidy, "Stress, cognition and health", Sigma Express (2002).

[3] J. S. Kim, K, R. Shin, "A Study on Depression, Stress, and Social Support in Adult Women", Korean Academy of Nursing Journal, vol. 34, no. 2, (2004), pp.352-361.

[4] E. J. Kim, K. J. Oh and E. H. Ha, "The Vulnerability of married women on depression: Focused on life stress and coping processes", Korean Journal of Psychology Women, vol. 4, no. 1, (1999), pp.1-14.

[5] I. S. Kim, "A Study on the Social Work Approach of Depressed Women", Social Science Research vol. 12, (1996), pp. 97-113. 
[6] R. C. Kessler, J. B. Turner, and J. S. House, "Effects of unemployment on health in a community survey: main modifying, and mediating effects", Journal of Social Issues vol. 44, no. 4, (1998), pp.69-85.

[7] G. W. Brown, and T. A. Mankowski, "Self-esteem, mood, and self-evaluation: Changes in mood and the way you see you", Journal of Personality and Social Psychology, vol. 64, (1993), pp.421130

[8] Y. S. Kim, “Color and Personal Color”, YeLim publication, (2004).

[9] H. J. Seo, "Correlation of nail color and psychological state - mainly women customers", A master's thesis of Chosun University, (2009).



\section{Authors}

Hee Jung Seo, she received her M.S. degrees in Beauty Cosmetic in Chosun University, Korea, in 2009 and completed Ph.D. degree in Perfume and Cosmetic in Chonnam National University, Korea, in 2012. She has been a CEO in Yes Beauty Square and a director in the International Society of Nail Beauty Design.

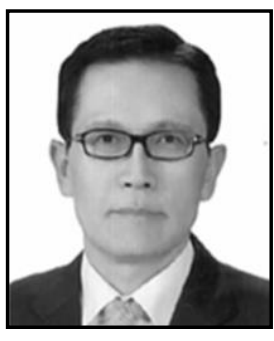

Joon Seub Cha, he received the $\mathrm{PhD}$ degree in Management Information Systems from Wonkwang University in 1995. He is a Professor in the Department of Internet Contents at Honam University at Gwangju, South Korea. His current research interests include System Analysis and design, SmartMedia, SmartValley, SmartWork, Big Data


SungKwan Kang, he received his B.S., M.S. and Ph.D. degrees in Electronic Engineering from Chosun University, Korea, in 1997, 1999 and 2005, respectively. He has been a CTO in Intersave Co., td. His research interests include game production technique, NFC technique and multimedia processing. 